\title{
ВОДОРАСТВОРИМОСТЬ, ЭМУЛЬГИРУЮЩАЯ \\ И ПЕНООБРАЗУЮЩАЯ СПОСОБНОСТИ ДИАЛКИЛФЕНИЛСУЛЬФОНАТОВ
}

\author{
(Представил О. Эйзен)
}

В настоящей статье изложены данные о водорастворимости, эмульгирующей и пенообразующей способности некоторых водомаслорастворимых диалкилфенилсульфонатов (ДАФС), синтез и поверхностно-активные свойства которых описаны ранее [1, 2 .

\section{Методика анализа}

Водорастворимость определяли по оптической плотности растворов ДАФС в зависимости от их концентрации в дистиллированной и жесткой $(4,7$ мә-экв/ $/)$ воде на аппарате ФЭК-56М при $22( \pm 1)^{\circ} \mathrm{C}$ по методике, примененной в работе $\left[{ }^{3}\right]$ (табл. 1).

Растворимость в жесткой воде - основной показатель технологических свойств ДАФС в случае их практического применения. В жесткой воде часть ДАФС оседает вместе с солями жесткости воды в виде нерастворимого осадка, в результате чего эффективная концентрация их в растворе уменьшается. Количество нерастворимого осадка измерялось путем выделения его из растворов, содержащих 0,00265 моль ДАФС на $1 \Omega$ воды, фильтрацией через мелкопористый фильтр № 16. При вычислениях предполагали, что реакционная способность ионов $\mathrm{Ca}^{++}$и $\mathrm{Mg}^{++}$с ДАФС оди наковая. Количество связанного в осадке ДАФС $(X$, вес. \%) вычисляли по урав. нению:

$$
X=\frac{200 \cdot B \cdot M_{8}}{M^{o c} \cdot C},
$$

где $B$ - вес осадка, г/л; $C$ - исходное количество ДАФС, $2 ;$ Мв - молекулярный вес ДАФС-Na; $\mathrm{M \theta}^{\circ \mathrm{c}}$ - молекулярный вес $\mathrm{Ca}^{++} \mathrm{Mg}^{++}$-ДАФС $\mathrm{C}_{2}$, усредненный пропорционально содержанию ионов $\mathrm{Ca}^{++}$и $\mathrm{Mg}^{++}$в воде. Результаты вычисления (средние $2-3$ определений) приведены в табл. 2. Погрешность измерения $\pm 6 \%$.

Нами изучалось также влияние триполифосфата натрия (50\% от ДАФС), используемого в качестве смягчителя воды, на количество связуемого в нерастворенный осадок ДАФС (табл. 2).

Пенообразующую способность определяли на аппарате Росс-Майлеа [4] в дистиллированной и в жесткой воде при $22( \pm 1)^{\circ}$. Эмульгирующую способность - методом конденсации водяного пара в белом вазелиновом масле [5]. Эмульгирующую способность индивидуальных первичных пара-ДАФС измеряли при их двух концентрациях: первая соответствовала $5 \times \mathrm{KKM}_{1}\left(\mathrm{KKM}_{1}-\right.$ критическая концентрация мицеллообразования [2]), вторая (постоянная для всех ДАФС) $-0,00265$ моль/л (рис. 1). Эмульгирующую способность вторичных ДАФС установили в диапазоне концентраций $0,01-0,1$ вес. $\%$ (рис. 2). Недостатком названного метода является неудовлетвори- 
Таблица I

Растворимость диалкилфенилсульфонатов в воде

\begin{tabular}{l|l|l}
\hline Диалкилфенилсульфонат & \multicolumn{2}{|c}{ Растворимость } \\
\cline { 2 - 2 } & вес. \% & $\left(\right.$ моль/л) $10^{-3}$ \\
\hline
\end{tabular}

\begin{abstract}
$n$-дигептил-ФС- $\mathrm{Na}^{\text {a }}$
$n$-диоктил-ФС-Na

$n$-динонил-ФС-Na

втор. дигептил-ФС- $\mathrm{Na}$

втор. дигептил-ФС-Na

втор. диоктил-ФС- $\mathrm{Na}$

втор. динонил-ФС-Na

втор. диоктил-ФС- $\mathrm{NH}_{4}$

втор, диоктил-ФС-ТЭА

ДАФС- ${ }^{\mathrm{r}}$
\end{abstract}

\section{Дистиллированная вода}

0,077
0,060
0,050
0,20
0,23
0,15
0,05
$(0,077)_{д}$
0,050
$(0,055)_{д}$
0,050
0,074

1,48

1,16

5,32

6,12

3,71

1,13

$(1,78)_{\text {д }}$

1,26

$(1,38)_{\text {д }}$

0,94

1,69

\section{Жесткая вода}

ДАФС- ${ }^{\mathrm{r}}$

втор. диоктил-ФС-Na

$\begin{array}{ll}0,025 & 0,57 \\ 0,039 & 0,96\end{array}$

a - на кривых зависимости оптической плотности от концентрации отсутствует резкий перегиб;

б - продукт на основе диалкилбензола, полученный одноступенчатым алкилированием ['];

в - сульфонат триэтаноламина;

г - технический сульфонат ['];

д - результаты кондуктометрического определения.

Таблица 2

Количества диалкилфенилсульфонатов, связанные

с солями жесткости воды, в нерастворимом осадке

(Концентрация ДАФС $-0,00265$ моль/л, жесткость воды $-4,7$ мг-экв/л)

\begin{tabular}{l|c|c|c|c}
\hline \multicolumn{1}{c|}{ Вещество } & $\begin{array}{c}\text { Вес } \\
\text { осадка, } \\
\text { a/л }\end{array}$ & $\begin{array}{c}\text { Молекуляр- } \\
\text { ный вес } \\
\text { ДАФС }\end{array}$ & $\begin{array}{c}\text { Молекуляр- } \\
\text { ный вес } \\
\text { осадка }\end{array}$ & $\begin{array}{c}\text { Количество } \\
\text { связанного } \\
\text { ДАФС, \% }\end{array}$ \\
\hline ДАФС-1 & 0,408 & $436 *$ & 857,44 & 41,5 \\
пара-дигептил-ФС-Na & 0,446 & 376,53 & 738,54 & 45,5 \\
пара-диоктил-ФС-Na & 0,736 & 404,59 & 794,64 & 69,8 \\
пара-динонил-ФС-Na & 0,906 & 432,64 & 850,75 & 80,3 \\
втор. динонил-ФС-Na & 0,748 & 432,64 & 850,75 & 66,3 \\
втор. динонил-ФС-Na $+50 \%$ & 0,124 & 432,64 & 850,75 & 11,0 \\
$\mathrm{Na}_{5} \mathrm{P}_{3} \mathrm{O}_{10}$ & & & &
\end{tabular}

* Молекулярный вес найден, а для остальных веществ вычислен.

тельная репродуцируемость данных и соответственно большая погрешность результатов. Кроме того, в начальной стадии анализа водомаслорастворимых ДАФС (наш случай) образуется, по-видимому, эмульсия типа в/м, так как масло в избытке, а в ходе анализа количество воды увеличивается за счет конденсирующего пара, и концентрация ДАФС снижается. В результате получается эмульсия типа м/в, что неодно. кратно наблюдалось в наших анализах. Кроме концентрации ДАФС на точку инверсии 


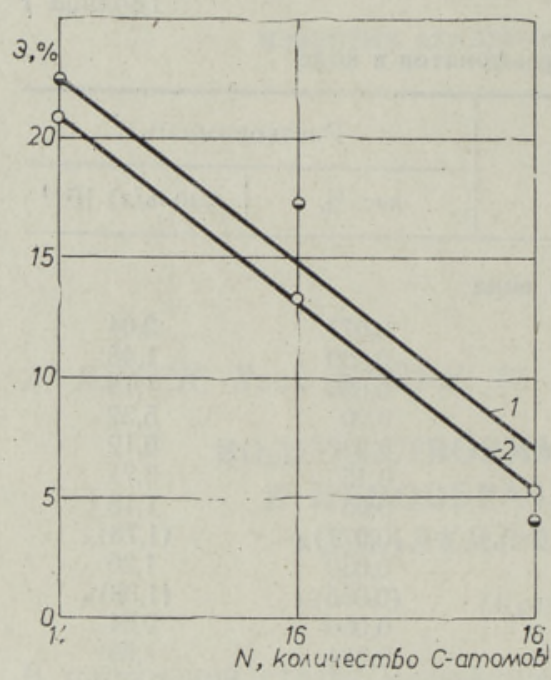

Рис. 1. Зависимость эмульгирующей способности (Э), определенной методом конденсации пара, растворов пара-ДАФС от длины алкильных цепей в бензоле $(N)$. 1 - концентращия ДАФС $5 \times \mathrm{KKM}_{1}, 2$ - концентрация ДАФС 0,00265 моль/л.

влияют температура, структура ДАФС и другие факторы, которые снижают точность определения и должны учитываться при оценке результатов, полученных методом конденсации пара. Поэтому параллельно мы испытали и другую методику определения эмульгирующей способности.

В мензурку объемом 100 мл, снабженную мешалкой и термостатированную при $22^{\circ}$ (или $90^{\circ}$ ), помещали $50^{\prime}$ мл раствора ДАФС и 10 мл вазелинового масла, которые перемешивали со скоростью 1200 об/мин в течение 3 мин. Затем определяли скорость расслоения эмульсии в растворе. Скорость вращения мешалки выбирали таким образом, чтобы при $22( \pm 1)^{\circ}$ эмульгирующая способность не зависела от скорости вращения мешалки. Этой зависимости не обнаружено при скоростях выше 1000 об/мин.

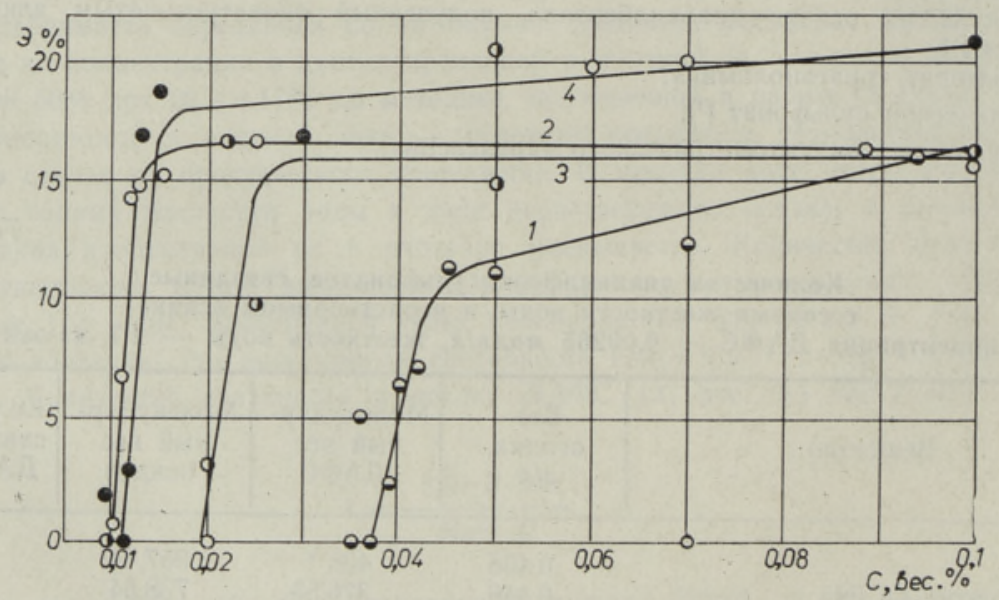

Рис. 2. Зависимость эмульгирующей способности (Э), определенной методом конденсации пара, растворов вторичных ДАФС и ДАФС-1 or концентрации. 1 - втор. дигептил-ФС-Na, 2 - втор. диоктил-ФС-Na, 3 - ДАФС-1, 4 - втор. динонил-ФС-Na.

\section{Результаты анализов и их обсуждение}

Растворимость изученных ДАФС с длиной алкильных цепей от дигептила до динонила в дистиллированной воде при $22( \pm 1)^{\circ}$ оказалась низкой и составляла $0,05-0,23$ вес. \% $(0,001-0,006$ моль/ $\Omega)$. Растворимость, однако, превышала $\mathrm{KKM}_{1}$ этих соединений в среднем в 3,15 раза, что согласуется с данными А. А. Солоницыной [3] о взаимосвязи $\mathrm{KKM}_{1}$ и растворимости анионных поверхностно-активных веществ (табл. 1). 
В жесткой воде такой закономерности не наблюдалось, и растворимость двух изученных продуктов была значительно выше их $\mathrm{KKM}_{1}$. В жесткой воде растворимость уменьшалась. С ростом алкильной цепи в молекуле ДАФС растворимость их уменьшается, причем у вторичных ДАФС она в $1,3-3$ раза выше, чем у пара-ДАФС.

Замена натриевого катиона на аммониевый или триэтанол-аммониевый увеличивает растворимость втор. диоктил-ФС почти в 3 раза, причем растворимость сульфоната аммония несколько выше $\left(1,32 \cdot 10^{-3}\right.$

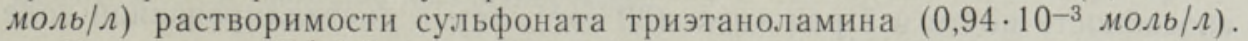

Количество ДАФС, связанных с солями жесткости воды в нерастворимом осадке, увеличивается с ростом молекулярного веса соединений (от 40 до $80 \%$; табл. 2). Добавление к растворам смягчителя воды $\left(0,05\right.$ вес. \% $\left.\mathrm{Na}_{5} \mathrm{P}_{3} \mathrm{O}_{10}\right)$.уменьшает количество осажденного ДАФС (напр., в случае втор. динонил-ФС-Na от 80,3 до 11,0 вес. \%; см. табл. 2).

Эмульгирующая способность первичных пара-ДАФС, определенная методом конденсации водяного пара при концентрациях $5 \times \mathrm{KKM}_{1}$ и 0,00265 моль/л, в дистиллированной воде (рис. 1) уменьшается с ростом длины алкильных цепей от дигептила до динонила. Эмульгирующая способность вторичных ДАФС, определенная этим же методом, увеличивается с ростом длины алкильных цепей. Подобное противоречие, по-видимому, объясняется вышеизложенными причинами, которые уменьшают точность применения метода. Эмульгирующая способность вторичных ДАФС и ДАФС-1 при концентрациях выше $K_{K} M_{1}$ находится в пределах $16-20 \%$, причем определенная в этих же условиях эмульгирующая способность вторичного додецилфенилсульфоната натрия при концентрации $5 \times \mathrm{KKM}_{1}($ моль/ $/)(1,0815$ вес. \%) составляла 14,5 $( \pm 1,5) \%$, а при концентрации 0,00265 моль/л $(0,087$ вес. \%), т. е. ниже $\mathrm{KKM}_{1}-1,0( \pm 1) \%$ (рис. 2$)$.

Эмульгирующая способность, определенная методом конденсации пара, увеличивается в зависимости от типа катиона в случае вторичных диоктилфенилсульфонатов (ДОФС) следующим образом:

$$
\begin{gathered}
\text { ДОФС-Na }<\underset{16 \%}{2} \text { ДОФС- } \mathrm{NH}_{4}<\text { ДОФС-ТЭА } \\
16 \% \\
17,8 \%
\end{gathered}
$$

Измерение эмульгирующей способности методом перемешивания дает в отношении репродуцируемости несколько лучшие результаты - максимальное отклонение данных составляло $3,5 \%$ (в среднем 1,5\%), а при применении метода конденсации пара - 5,0\% $(2 \%)$ рис. 2$)$. Метод перемешивания значительно

Рис. 3. Зависимость пенообразующей способности от концентрации ДАФС в дистиллированной (непрерывная линия) и жесткой (прерывистая линия) воде при $22( \pm 1)^{\circ} \mathrm{C} .1-$ втор. дигептилФС-Na, 2 - ДАФС-1, 3 - втор. диоктил-ФС-Na, $4-$ втор. динонил-ФC-Na.

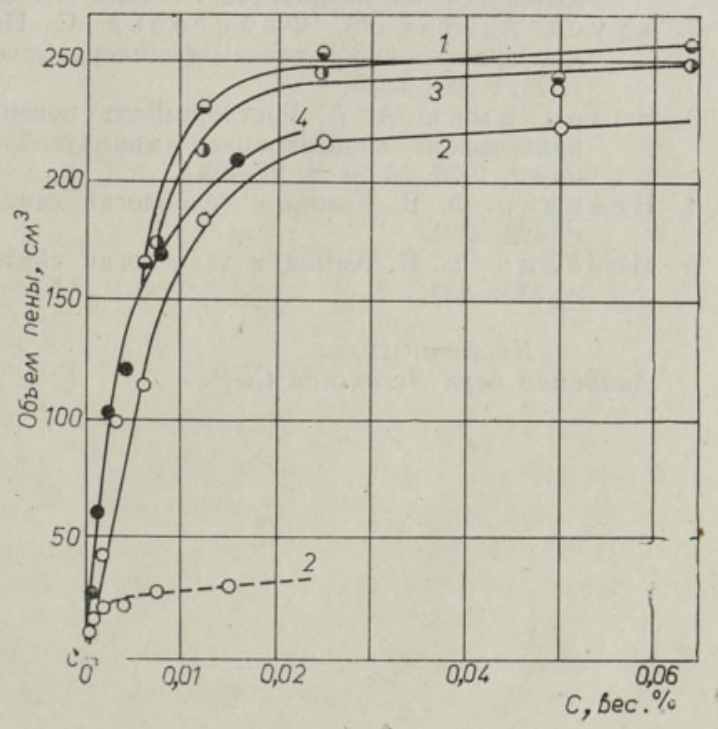


проще и менее продолжителен. Однако абсолютные значения эмульгирующей способности, полученные методом перемешивания при $22^{\circ}$, для ДАФС-1 и втор. диоктил-ФС-Na на 5-6\% выше, чем результаты, полученные методом конденсации пара.

ДАФС образуют в дистиллированной воде при концентрациях выше

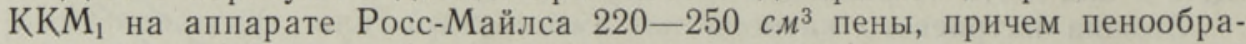
зующая способность увеличивается с уменьшением молекулярного веса̊ их (напр., вторичные ДАФС; рис. 3). В жесткой воде пенообразующая способность почти в 7 раз ниже $\left(30 \mathrm{~cm}^{3}\right)$, чем в дистиллированной воде (напр., у ДАФС-1).

Пеноустойчивость у индивидуальных вторичных ДАФС в дистиллированной воде при концентрациях выше $\mathrm{KKM}_{1}$ высокая $(0,95-0,97)$, у ДАФС-1 в жесткой воде - низкая и резко падает после максимума $(0,70)$ при концентрации 0,075 вес. \%.

\section{Выводы}

1. Растворимость изученных ДАФС в дистиллированной воде при $22( \pm 1)^{\circ} \mathrm{C}$ находится в пределах $0,05-0,23$ вес. \% $(0,001-0,005$ моль/ $)$ и превышает значение $\mathrm{KKM}_{1}$ в среднем в 3,15 раза. В жесткой воде растворимость у двух изученных ДАФС в $3-3,8$ раза ниже, чем в дистиллированной.

2. Эмульгирующая способность ДАФС в отношении вазелинового масла почти на $5 \%$ выше эмульгирующей способности втор. додецилфенилсульфоната натрия.

3. Пенообразующая способность и пеноустойчивость ДАФС в жесткой воде низкие, что позволяет применять их в технологических процессах.

\section{Л И Т Е Р А У РА}

1. Кууск А., В ооре Х., $\Phi$ айнгольд С. Синтез индивидуальных и технических диалкилфенилсульфонатов. - Изв. АН ЭССР. Хим., 1980 , т. 29 , с. $38-43$.

2. Кууск А., Ээк М., Фай нгольд С. Поверхностно-активные свойства водомаслорастворимых диалкилфенилсульфонатов. - Изв. АН ЭССР. Хим., 1979, т. 28 , c. $261-265$.

3. Солоницын а А. А. Растворимость поверхностно-активных веществ и связь с критической концентрацией мицеллообразования. - Сб. тр. Моск. технол. ин-та, 1976 , № 28 , с. $21-23$.

4. Не волин Ф. В. Химия и технология синтетических моющих средств, М., 1971, c. $398-399$.

5. Не в олин Ф. В. Химия и технология синтетических моющих средств. М., 1964, c. $335-337$.

Институт химии

Академии наук Эстонской ССР
Поступила в редакцию 12/X 1979 
A. KUUSK, Heli VOORE, M. EEK, S. FAINGOLD

\section{DIALKUOLFENOULSULFONAATIDE LAHUSTUVUS VEES, EMULGEERIMIS- JA VAHUMOODUSTAMISVÕIME}

Dialküülfenüülsulfonaatide $\mathrm{C}_{7}-\mathrm{C}_{9}$ kolorimeetriliselt määratud lahustuvus on $22 \pm 1{ }^{\circ} \mathrm{C}$ juures $0,05-0,23 \%$ (karedas vees $3-3,8$ korda madalam), emulgeerimisvõime on kõrgem kui naatriumdodetsüülfenüülsulfonaadil ja vahumoodustamisvồime on karedas vees madal (ca $30 \mathrm{~cm}^{3}$, määratud Ross-Mylesi järgi).

A. KUUSK, Heli VOORE, M. EEK, S. FAINGOLD

\section{WATER SOLUBILITY, EMULSIFYING AND FOAMING ABILITY OF DIALKYLPHENYL SULPHONATES}

The solubility of dialkylphenyl sulphonates (DAPS) was estimated colorimetrically, being within intervals of $0.05-0.23 \%$. Solubility in hard water was $3-3.8$ times lower. Emulsifying ability of DAPS was about $5 \%$ higher than that of sodium dodecylphenyl sulphonate. Foaming ability of DAPS in hard water was low (about $30 \mathrm{~cm}^{3}$ by RossMyles). 